\title{
Le perroquet
}

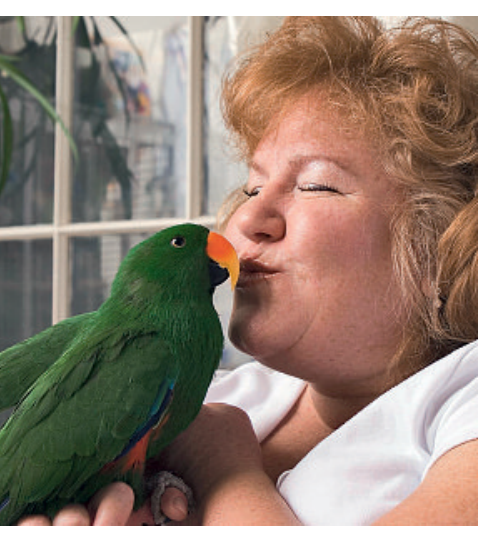

Grâce à une chimiothérapie qui aura coûté quelque 100000 dollars, une patiente domiciliée en Floride a survécu un an de plus que le pronostic de ses médecins. Elle est décédée en mordant dans son dessert préféré, un muffin aux myrtilles. Non, mon article ne traite pas de la réforme de santé d'Obama, mais d'un perroquet.

La médecine vétérinaire est un secteur de la santé en plein essor et nos confrères se sont armés de presque tout l'arsenal diagnostic et thérapeutique utilisé en médecine humaine.

Les plus de 7 millions d'animaux domestiques que compte la Suisse ont donné naissance, comme dans les autres pays industrialisés, à un juteux marché. Les suisses dépensent plus d'un milliard de francs par an rien qu'en nourriture et accessoires pour leurs animaux. Près de la moitié des ménages entretiennent un animal, soit 1,3 million de chats, un demi-million de chiens, rongeurs, oiseaux, poissons et reptiles, sans compter les chevaux. Coop et Migros présentent des surfaces commerciales dédiées à la nourriture pour animaux beaucoup plus importantes que celles destinées à la nourriture pour bébés. Leurs arbres à chats grimpent quasiment jusqu'au ciel. Rien d'étonnant donc que bon nombre de ces friandises se retrouvent ensuite sur la liste de courses des couches de population les plus défavorisées, car outre les conserves de viande bon marché, on y trouve de tout, des régimes basses calories, aux boissons diététiques en passant par les snacks. Le domaine des accessoires n'est pas non plus en reste, car en plus des laisses et de l'herbe à chat, on peut désormais aussi acheter des coussins en épeautre, des buggys et les lunettes de soleil pour chien, des parfums pour rats, des manteaux pour iguanes, sans compter les bottines et parapluies pour tout ce qui compte des pattes. On en viendrait presque à croire que les animaux domestiques sont meilleurs que les humains. Or, ils n'en partagent pas moins certaines maladies avec leurs propriétaires: obésité, diabète, arthrose, affections coronariennes et dentaires.

L'humanisation des animaux a fait son entrée dans la médecine vétérinaire. Il suffit de cliquer sur le site de la faculté vétérinaire de l'université de Zurich (www. vet.uzh.ch) pour s'en rendre compte. On y découvre de nombreuses histoires de guérison émouvantes tel ce caniche atteint du syndrome de Cushing, ce chat souffrant d'une affection de la moelle épinière, cette chouette hulotte à l'aile cassée, ce poney à nouveau capable de faire des cabrioles ou ce boa constrictor souffrant de parasites pulmonaires. Ostéosynthèses, échographies, endoscopies, radiothérapies, transfusions sanguines, médicaments et IRM sont monnaie courante. De nombreuses races de chiens élevés pour avoir une grande tête, ne peuvent accoucher que par césarienne. Une prothèse de la hanche sans ciment ou un pacemaker font partie de la routine au même titre que, dans certaines cliniques privées américaines, la liposuccion, la correction des rides ou les testicules en silicone pour les chiens castrés. Dans un pays où une propriétaire fait tatouer les paupières de son toutou préféré pour un concours de miss, tout semble permis. Les bêtabloquants épargnent aux cochons le stress de l'abattage et le coach pour animaux se charge de traiter les névroses animales par une psychothérapie comportementale.

Notre rapport aux bêtes est pour le moins schizophrène. Au jardin d'enfants et en prison, les animaux doivent transmettre des compétences sociales et favoriser la guérison des malades dans le cadre thérapeutique. Or on oublie de dire que la première loi moderne de protection des animaux a été introduite en Allemagne en 1933 et qu'elle est restée en vigueur jusqu'en 1972. Le lien avec la nature et l'amour des animaux faisaient partie des caractéristiques de la race nordique. Une idéologie qui prévaut encore en partie chez certains défenseurs des animaux. L'initiative en faveur des avocats pour les animaux a été rejetée avec véhémence - à juste titre peut-être - en mars dernier. Mais que l'on m'explique comment il est possible qu'un amour sélectif des animaux cohabite sans problèmes avec des fabriques d'animaux et des listes de plus en plus longues d'espèces disparues ou menacées. Celui qui parle de manger des oiseaux ou de morsures et de crottes de chiens risque de recevoir de méchantes lettres de lecteurs. L'une des multiples motifs de ce comportement réside peut-être dans le fait que, dans les espaces urbains, la nature n'existe plus qu'entre nos quatre murs. Au final, cette nature de substitution en appartement profitera à toute une industrie funéraire avec urnes, cercueil et rites funéraires. Le dernier voyage vers le centre de ramassage des cadavres à définitivement fait son temps.

En Floride, le perroquet «Areba» est mort à 43 ans. Mais malgré tous les progrès réalisés, ni la médecine humaine ni la médecine vétérinaire n'atteindront le potentiel de consolation des anciens Egyptiens où oiseau et maître momifiés pouvaient attendre ensemble leur résurrection.

Erhard Taverna 